\title{
CONTAGEM DE BACTÉRIAS LÁTICAS VIÁVEIS EM LEITES FERMENTADOS
}

\section{VIABLE LACTIC ACID BACTERIA IN FERMENTED MILKS}

\author{
Ester de Almeida Machado Oliveira ${ }^{1}$ \\ Caroline Luise Soldi ${ }^{2}$ \\ Cristiano Caveião ${ }^{3}$ \\ Willian Barbosa Sales ${ }^{4}$
}

\begin{abstract}
Resumo: O leite fermentado é um alimento funcional, que fornece benefícios por meio das culturas probióticas. Objetivou-se verificar quantidade de microrganismos viáveis e a temperatura de comercialização das bebidas láticas (leites fermentados) de um supermercado da cidade de Curitiba-PR e comparar se estavam de acordo com a Instrução Normativa n 46, de 23 de outubro de 2007, do Ministério de Agricultura, Pecuária e Abastecimento (MAPA). As temperaturas foram aferidas no momento da aquisição dos produtos e, logo em seguida, levados em caixa isotérmica para o Laboratório de Microbiologia. Foram realizadas diluições seriadas e semeadas em ágar Man Rogosa \& Sharpe (MRS), e incubadas a $35 \pm 1^{\circ} \mathrm{C}$ por 4 dias. Na sequência, Coloração de Gram, Teste de Catalase, e a contagem das bactérias láticas em UFC/ml (unidades formadoras de colônias por mililitro). Todas as 10 amostras analisadas estavam sendo comercializadas na temperatura preconizada, esta variou entre os valores mínimo e máximo $2,9^{\circ} \mathrm{C}$ e $7^{\circ} \mathrm{C}$, com média de $\pm 6,14^{\circ} \mathrm{C}$ e desvio padrão de 1,635 . Foram encontradas

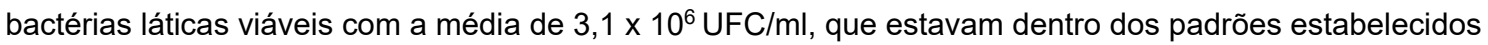
pela Instrução Normativa nº46, de 23 de Outubro de 2007, do MAPA, de, no mínimo, $10^{6}$ UFC/g e temperatura de comercialização não superior a $10^{\circ} \mathrm{C}$.
\end{abstract}

Palavras-chave: Controle de qualidade; probióticos; Lactobacillus.

Abstract: Fermented milk is a functional food, which provides benefits by the probiotic cultures. The objective was to verify the quantity of viable microorganisms and the temperature of commercialization of the lactic beverages (fermented milks) of a supermarket in the city of Curitiba-PR and to compare if they were in agreement with the Normative Instruction $n^{\circ} 46$ of October 23, 2007, of the Ministry of Agriculture, Livestock and Supply (MAPA). The temperatures were measured at the moment of purchase of the products and soon afterwards, they were taken in an isothermal box to the Laboratory of Microbiology. Serial dilutions were performed and seeded on Man Rogosa \& Sharpe agar (MRS), and incubated at $35 \pm 1^{\circ} \mathrm{C}$ for 4 days, following Gram Stain, Catalase (-) Test, and lactic bacteria counting in $\mathrm{CFU} / \mathrm{ml}$, according to the Normative Instruction $\mathrm{N}^{\circ} 46$ of October 23,2007 . All 10 samples analyzed were commercialized within the recommended temperature $\pm 6,14^{\circ} \mathrm{C}$, and the standard deviation was 1.635 . The minimum and maximum values between $2.9^{\circ} \mathrm{C}$ and $7^{\circ} \mathrm{C}$ were found viable lactic acid bacteria with a mean of $3.1 \times 10^{6} \mathrm{CFU} \mathrm{ml^{-1 }}$, both of which were within the standards established by the Normative Instruction $N^{\circ} 46$ of October 23, 2007, of MAPA, at least $10^{6} \mathrm{CFU} / \mathrm{ml}$ and commercialization temperature not higher than $10^{\circ} \mathrm{C}$.

Keywords: Quality control; probiotics; Lactobacillus.

\footnotetext{
${ }^{1}$ Centro Universitário Autônomo do Brasil, Brasil. E-mail: sterbebeia@hotmail.com.

2 Centro Universitário Autônomo do Brasil, Brasil. E-mail: carolsoldi.cs@gmail.com.

3 Centro Universitário Autônomo do Brasil, Brasil. E-mail: cristiano_caveiao@hotmail.com.

${ }^{4}$ Centro Universitário Autônomo do Brasil, Brasil. E-mail: willianbarbosasales@gmail.com.

Revista Univap - revista.univap.br

São José dos Campos-SP-Brasil, v. 24, n. 46, dez. 2018. ISSN 2237-1753
} 


\section{INTRODUÇÃO}

Como uma das principais características da sociedade moderna, o tempo escasso e o ritmo de vida acelerado nos forçam a realizar as refeições em um tempo cada vez mais célere. A indústria alimentícia, assim como a ciência tecnológica, tem produzido alimentos capazes de nutrir, resultando na promoção do bem-estar, da saúde e reduzindo riscos de doenças. Nesse cenário, o uso de alimentos com propriedades funcionais tem aumentado (MAIA; SANTOS, 2006).

A introdução de alimentos com propriedades funcionais à dieta faz-se um importante aliado no combate a diversas patologias, pois parece promover a redução da taxa de colesterol, controle glicêmico, redução da obstipação ou diarreia e estimula o sistema imune, pois aumenta a permeabilidade intestinal, permitindo que os nutrientes sejam absorvidos com uma maior facilidade (FLESCH; POZIOMYCK; DAMIN, 2014).

A bebida lática, como o leite fermentado, é considerada um alimento funcional e já faz parte da alimentação de muitas pessoas, devido à sua praticidade. Confere benefícios a seu hospedeiro, quando administrada em doses recomendadas.

Nessas bebidas, são encontradas culturas probióticas que ao se fixarem no cólon humano promovem efeito terapêutico. Para tal feito, é necessário que as bactérias láticas estejam viáveis durante toda a vida de prateleira do produto (FLESCH; POZIOMYCK; DAMIN, 2014; HAENLEIN, 2007).

Os nômades foram os produtores pela primeira vez do leite fermentado. Eles armazenavam o leite oriundo da ordenha em reservatórios feitos de estômago de bode. Essa estocagem era favorecida em decorrência do clima árido e seco da região da Eurásia, o que, consequentemente, proporcionava a proliferação de bactérias, que modificaram a estrutura do alimento, tornando-o sensorialmente atrativo para aqueles indivíduos, além de ser uma forma de conservação da substância láctea (HAENLEIN, 2007; YILDIZ, 2010).

Para alcançar os benefícios pelo leite fermentado, sendo essa bebida probiótica, o conteúdo de cada bebida lática deve apresentar uma contagem mínima de $10^{6}$ unidades formadoras de colônia por $\mathrm{mL}$ durante toda a vida de prateleira do produto, $\mathrm{e}$ a temperatura de comercialização não pode ser superior a $10^{\circ} \mathrm{C}$. A Instrução Normativa $n^{\circ} 44$, de 15 de dezembro de 2015 do MAPA, caracteriza probióticos como cepas de microrganismos vivos (viáveis) que agem como auxiliares na recomposição da microbiota do trato digestório dos animais, contribuindo para o seu equilíbrio (BRASIL 2015).

Microrganismos vivos (viáveis), que agem como auxiliares na recomposição da microbiota do trato digestório dos animais, contribuindo para o seu equilíbrio (BRASIL 2015). 
A Food and Agriculture Organization (FAO) e a Organização Mundial de Saúde (OMS), em 2002, consideraram próbióticos como produtos que contêm microrganismos vivos (TAVERNITI; GUGLIELMENTTI, 2011). O consumo de probióticos tem ajudado a melhorar as desordens do metabolismo humano, permitindo ao paciente um prognóstico melhor, principalmente no perfil lipídico, reduzindo os níveis séricos de colesterol. Esses resultados são explicáveis por vários mecanismos de ação que incluem: diminuição de absorção intestinal de colesterol, modulação de metabolismo lipídico por meio de citocinas e adipocinas, incorporação ou assimilação de colesterol na membrana intestinal e inibição de transportadores intestinais de colesterol (VILLENA; KITAZAWA, 2017). Além disso, também ocorre a modulação do sistema imunológico, melhorando, assim, as suas funções (RIZZARDINI et al., 2012). Os lactobacilos inibem a proliferação de microrganismos não benéficos, aumentando a captação de nutrientes e produção de ácidos orgânicos que reduzem o $\mathrm{pH}$ do intestino, diminuindo, assim, o crescimento de bactérias patogênicas (FLESCH; POZIOMYCK; DAMIN, 2014; SHARMA et al., 2017).

Vários gêneros bacterianos e algumas leveduras são utilizados como microrganismos probióticos, incluindo os gêneros Lactobacillus, Leuconostoc, Bifidobacterium, Propionibacterium, Enterococcus e Saccharomyces. No entanto, estudos têm demonstrado que as principais espécies com características probióticas são o Bifidobacterium spp., Lactobacillus acidophius e Lactobacillus casei. Atualmente, as principais culturas utilizadas pela indústria como probióticos incluem Lactobacillus e, Bifidobacterium que possuem um longo histórico na produção de derivados lácteos e também, são encontradas como parte da microbiota gastrointestinal do homem, além da levedura Saccharomyces cerevisiae boulardii (BALLARDIN et al., 2014).

A fim de se obter os mesmos efeitos de probióticos como o Lactobacillus casei no trato gastrointestinal, tem sido utilizada uma fibra como prébiótica, a polidextrose. Tratase de polímeros de glicose formada sinteticamente, obtida pela policondensação térmica à vácuo da glicose com uma pequena quantidade de sorbitol e ácido cítrico como catalisador, não possui sabor residual e totaliza $90 \%$ de fibra, o que a torna um ingrediente versátil, possui baixo valor calórico apenas (1 Kcal/g) e solúvel em água (MOTA, et al., 2011). Em estudos, bolos e pães, enriquecidos com polidextrose, favorecem a proliferação de probióticos intestinais, propiciando a promoção de uma vida mais saudável (MOTA et al., 2011; BUENO, 2013). Os prébióticos podem ser definidos por serem capazes de provocar mudanças na composição e na atividade da microbiota intestinal, pois possuem, em sua composição, ingredientes não-digeríveis, trazendo bem estar à saúde do hospedeiro (COSTA et al., 2013).

Tanto os probióticos quanto os prebióticos devem ser ingeridos diariamente, a fim de se obter um efeito contínuo. A ingestão mínima diária, para que sejam obtidos os benefícios funcionais, foram observados na quantidade de 100 gramas diárias de produtos lácteos, que contenham probióticos, durante 15 dias de uso contínuo (SAAD, 2006). 
É necessário manter o controle de qualidade dos produtos alimentícios ofertados às pessoas e, para isso, os microrganismos devem estar viáveis durante toda a vida de prateleira do produto. As bactérias láticas prolongam a vida de prateleira do produto, pois mantêm a sua qualidade nutricional, inibindo as bactérias patogênicas ou deteriorantes (SHARMA et al., 2017). Diante do exposto, objetivou-se, neste estudo, verificar quantidade de microrganismos viáveis e a temperatura de comercialização das bebidas láticas (leites fermentados) de um supermercado da cidade de Curitiba-PR e comparar se estavam de acordo com a Instrução Normativa $n^{\circ} 46$, de 23 de outubro de 2007, do MAPA.

\section{MÉTODOS}

Trata-se de um estudo quantitativo de análise microbiológica de leite fermentado, escolhido de forma aleatória, dentro do prazo de validade, comercializado em um supermercado de Curitiba-PR. A pesquisa foi realizada no período de maio a junho de 2017, em 10 amostras de leite fermentado, de diferentes marcas, que foram adquiridas em um mesmo supermercado e analisadas em triplicatas.

Como critérios de inclusão foram selecionadas amostras de leite fermentado dentro do prazo de validade que estavam sendo comercializado entre $0^{\circ} \mathrm{C}$ a $10^{\circ} \mathrm{C}$, cujas embalagens estavam íntegras e possuíam a descrição de presença de bactérias láticas vivas. Foram excluídos leites fermentados com peso descrito nas embalagens maior de 80 gramas e menor que 75 gramas, e, também, aqueles acrescidos de frutas.

Após a seleção das amostras, foi aferida a temperatura por um termômetro digital infravermelho calibrado, em que o laser foi direcionado para o centro geométrico da embalagem do produto. Foi realizada a leitura e o registro dos dados, que foram codificados em amostra 1, amostra 2, amostra 3, sucessivamente. Em seguida, foram acondicionadas em caixa de material isotérmico e transportadas, imediatamente, ao laboratório de microbiologia.

Para análise microbiológica do leite fermentado, todo o material foi previamente esterilizado e manipulado próximo ao bico de bussen com a chama a meia altura. Foram utilizados $25 \mathrm{~mL}$ de cada amostra de leite fermentado homogeneizado com $225 \mathrm{ml}$ de água peptonada estéril a $1 \% \mathrm{com} \mathrm{pH}$ equilibrado com tampão fosfato, para evitar injúria às células. Foi realizada a homogeneização das amostras em um liquidificador, devidamente higienizado, para romper as cadeias de bactérias láticas e resultar em contagens mais acuradas das bactérias presentes. O copo do liquidificador e o diluente estavam resfriados a $\pm 10^{\circ} \mathrm{C}$ antes da homogeneização (FORSYTHE, 2013; SILVA; JUNQUEIRA; SILVEIRA, 2001).

Foram realizadas diluições seriadas, compostas de $9 \mathrm{ml}$ de água peptonada e 1 $\mathrm{ml}$ de amostra, obtendo diluições $10^{-1}, 10^{-2}$ e $10^{-3}$. Foi inoculado $1 \mathrm{~mL}$ de cada diluição 
em placas de petri estéreis vazias, adicionando, em seguida, o meio de cultura ágar de Man Rogosa \& Sharpe (MRS). As placas foram incubadas invertidas acondicionadas em jarro com atmosfera anaeróbia a $35 \pm 1^{\circ} \mathrm{C}$, por 4 dias (FORSYTHE, 2013; SILVA; JUNQUEIRA; SILVEIRA, 2001).

Foi realizado o teste de catalase colocando, na lâmina de vidro, uma gota de água estéril e uma porção do isolado de cultura, retirado da placa de petri com a alça bacteriológica. Em seguida, foi adicionada uma gota de peróxido de hidrogênio a 3\%. Não havendo bolhas de ar, indicativo de teste negativo sendo confirmadas como bactérias láticas (FORSYTHE, 2013).

As placas selecionadas para contagem estavam próximas a 300 UFC. Foram selecionadas cinco colônias presentes nas placas e submetidas à coloração de Gram e teste de catalase. As culturas Gram positivas (cocos ou bastonetes) e catalase negativas foram confirmadas como bactérias láticas. Posteriormente foi calculado 0 número de unidades formadoras de colônias (UFC/ml) em função do número de colônias confirmadas e da diluição inoculada. A identificação e caracterização das bactérias láticas foi possível por intermédio do crescimento em meio de cultura específico, como ágar MRS. A coloração de Gram serviu para verificação da morfologia bacteriana (cocos ou bastonetes). O teste de catalase permitu separar os microrganismos catalase negativos dos produtores de catalase. A enzima catalase converte o peróxido de hidrogênio em oxigênio e água, a liberação do oxigênio se observa pela liberação de bolhas (SILVA; JUNQUEIRA; SILVEIRA, 2001).

A contagem de colônias de bactérias ácido láticas das placas foi feita por meio do cálculo manual pelo contador de colônias. Obteve-se resultados multiplicando-se o número de colônias enumeradas por 10 e pelo inverso da diluição selecionada para contagem. Todos os resultados foram expressos como Unidades Formadoras de colônia (UFC) por mililitro do produto (BRASIL, 2007).

Os resultados foram registrados e analisados por meio da estatística descritiva simples, por intermédio de um banco de dados elaborado com auxílio do programa Microsoft EXCEL ${ }^{\circledR}$. Foi considerada a média das unidades formadoras de colônias e a temperatura de comercialização de cada produto e realizada a classificação de acordo com as adequações aos valores preconizados pela Instrução Normativa $n^{\circ} 46 / 2007$, do MAPA (BRASIL, 2007).

\section{RESULTADOS E DISCUSSÕES}

Após a semeadura das placas e decorrido o período de incubação das dez amostras de leite fermentado, realizou-se a contagem, somatório e a média do valor das UFC presentes nas diluições. Os produtos lácteos fermentados com alegação funcional analisados possuíam uma média de $3,1 \times 10^{6} \mathrm{UFC} / \mathrm{ml}$, estando de acordo com a 
Instrução Normativa $n^{\circ} 46 / 2007$ do MAPA, bem como as temperaturas de comercialização com uma média de $5,5^{\circ} \mathrm{C}(\mathrm{DP} \pm 1,58)$.

Na Tabela 1, estão descritas as temperaturas aferidas no momento da aquisição do produto e a adequação à Instrução Normativa n 46, de 23 de outubro de 2007 (BRASIL, 2007). Todas as amostras apresentaram 100\% de adequabilidade à norma em vigor, respondendo a um dos objetivos do estudo. Vale ressaltar que as variações de temperaturas ocorreram devido ao diferente posicionamento, dos frascos das diversas marcas, nas gôndolas do supermercado.

Tabela 1 - Temperatura de leite fermentado aferida no momento da compra.

\begin{tabular}{cccc}
\hline Amostra & Temperatura $\left({ }^{\circ} \mathrm{C}\right)$ & $\begin{array}{c}\text { Adequação à } \\
\text { legislação }\end{array}$ & $\begin{array}{c}\text { Frequência relativa } \\
(\%) \text { de adequação à } \\
\text { legislação }\end{array}$ \\
\hline 1 & $6,5^{\circ} \mathrm{C}$ & Adequado & 100 \\
2 & $5,9^{\circ} \mathrm{C}$ & Adequado & 100 \\
3 & $7,0^{\circ} \mathrm{C}$ & Adequado & 100 \\
4 & $7,0^{\circ} \mathrm{C}$ & Adequado & 100 \\
5 & $4,3^{\circ} \mathrm{C}$ & Adequado & 100 \\
6 & $4,5^{\circ} \mathrm{C}$ & Adequado & 100 \\
7 & $2,9^{\circ} \mathrm{C}$ & Adequado & 100 \\
8 & $6,5^{\circ} \mathrm{C}$ & Adequado & 100 \\
9 & $3,4^{\circ} \mathrm{C}$ & Adequado & 100 \\
10 & $7,0^{\circ} \mathrm{C}$ & Adequado & 100 \\
\hline
\end{tabular}

As temperaturas apresentaram-se dentro dos valores preconizados pela Instrução Normativa $n^{\circ} 46$, de 23 de outubro de 2007 (MAPA), diferentemente do estudo de Silva, Ueno (2013) que avaliou os iogurtes acrescidos de bactérias láticas nos sabores: natural, coco, ameixa e morango, pertencentes a 4 marcas coletadas em 4 supermercados diferentes, comprovando-se o baixo crescimento das UFC, sendo apontada a temperatura como causa sua da pequena proliferação.

Ao se observar e avaliar os resultados obtidos na Tabela 2 confirmou-se a presença de bactérias láticas durante a vida de prateleira do produto. Sendo assim, de importância fisiológica à saúde do consumidor, propiciando efeito terapêutico. Os produtos com alegação funcional devem ter bactérias probióticas com populações de, no mínimo, $10^{6}$ unidades formadoras de colônia por mililitro (UFC/ml) de leite fermentado. As dez amostras de diferentes marcas estão com contagem acima da preconizada por legislação em vigor, Instrução Normativa $n^{\circ} 46$, do Ministério da Agricultura, Pecuária e Abastecimento, de 23 de outubro de 2007 (BRASIL, 2007). 
Tabela 2 - Classificação de adequação dos produtos lácteos fermentados de acordo com o número de unidade formadoras de colônias UFC/ml.

\begin{tabular}{ccc}
\hline Amostra & UFC/mI & Adequado \\
& & $\begin{array}{c}\text { Instrução Normativa } \\
\mathbf{4 6 / 2 0 0 7}\end{array}$ \\
\hline 1 & $3,6 \times 10^{6}$ & Adequado \\
3 & $2,2 \times 10^{6}$ & Adequado \\
4 & $3,2 \times 10^{6}$ & Adequado \\
5 & $1,9 \times 10^{6}$ & Adequado \\
6 & $3,9 \times 10^{6}$ & Adequado \\
7 & $3,8 \times 10^{6}$ & Adequado \\
8 & $3 \times 10^{6}$ & Adequado \\
9 & $2,5 \times 10^{6}$ & Adequado \\
10 & $3,5 \times 10^{6}$ & Adequado \\
\hline
\end{tabular}

No estudo de Castilho et al. (2012), as amostras avaliadas apresentaram inconformidade no número de colônias, sendo apontada a temperatura inadequada como fator contribuinte para ineficácia dos produtos, contribuindo para o baixo valor de unidades formadoras de colônias.

O mesmo foi evidenciado em outro estudo, no qual se verificou a vida útil de prateleira de bebidas fermentadas, submetendo 5 marcas de iogurtes com polpa de fruta sabor morango, com bactérias láticas, no qual efetuou-se a contagem de bactérias viáveis totais durante 44 dias, nas temperaturas de $7^{\circ} \mathrm{C}, 3^{\circ} \mathrm{C}, 15^{\circ} \mathrm{C}$ e $11^{\circ} \mathrm{C}$, como condições de processamento, estocagem, distribuição e comercialização, respectivamente. O tempo de vida médio encontrado foi de 33,5 dias, sendo comprovado que quanto maior a temperatura, no caso das temperaturas de distribuição de comercialização acima da preconizada por legislação vigente, maior é a taxa de deterioração diária do produto. Nas temperaturas de processamento e estocagem, também se observa a degradação da população de unidades formadoras de colônias, porém em números menores. Diferentemente dos estudos supracitados, o presente trabalho comprovou a adequabilidade de temperatura em todas as marcas. Vale salientar que as gôndolas do supermercado em que foram adquiridas as amostras são do tipo fechado (com porta), o que não propicia tanta perda de temperatura com o meio externo, o que pode ser considerado como fator determinante para a viabilidade dos microrganismos (ALMEIDA et al., 2015).

Os leites fermentados apresentam propriedades terapêuticas por serem suplementados com bactérias, como lactobacilos, bifidobactérias e estreptococos (não patogênico) (ROBERFROID, 2002). A origem das bactérias advém do trato gastrointestinal humano e que conferem ao consumidor benefícios fisiológicos, sendo, portanto, classificado como alimento funcional (NESPOLO et al., 2014). 
Em um estudo realizado com o comparativo genômico entre 42 cepas do microrganismos $L$. salivarius, foi observado que tais cepas possuem funcionalidade igual às cepas do estudo em questão, que são espécies do gênero Lactobacillus. Ressaltase que, a partir da comprovação das propriedades específicas de L. salivarius, comprovado por meio da coloração de Gram, que este pode ser usado na nutrição como probiótico e na preservação de alimentos, prolongando a vida de prateleira dos produtos fermentados, o que corrobora com o que foi observado neste estudo, no qual foi visualizada em microscópio óptico a forma de bastonetes e positividade de cada cultura na lâmina, comprovando-se cultura de bactéria lática como bacilos Gram-positivos (HARRIS et al., 2017).

A cultura do gênero Lactobacillus paracasei, como cepas probióticas, foi enumerada no estudo de Scariot et al. (2017), realizado durante 30 dias, em que se induziram as cepas de L. paracasei em iogurtes e quantificou-se por meio da estimativa da quantidade celular de microrganismos viáveis, tal como o presente estudo. Após 30 dias inoculadas as bactérias probióticas foram 8 log UFC/ml, aproximadamente, contagem suficiente para obter benefícios à saúde humana como iogurte probiótico.

Observa-se que com o uso de leite fermentado com as mais diversas cepas podese obter resultados semelhantes na microbiota intestinal, desde que tenha as unidades formadoras de colônias em quantia satisfatória, tal como o resultado aqui encontrado (AYENI; RUPPITSCH, 2017).

O teste de catalase negativo e a observação em microscópio de bacilos Gram positivos confirmou a presença de bactéria lática em $100 \%$ das amostras submetidas ao estudo e, desse modo, esse alimento pode ser usado pelos consumidores (ROBERFROID, 2002).

Ressalta-se que os testes feitos neste estudo são amplamente utilizados em outros estudos da área e que, em um estudo recente, foi desenvolvida uma técnica já comprovada em laboratório por $\mathrm{He}$ et al. (2017), a qual detectou, com rapidez e segurança, a existência de cultura lática viva e sua viabilidade por meio do método de fluorescência, no qual se faz mancha de ácido nucleico verde-fluorescente de SYTO 9, com o Ciclometro de fluxo de alta sensibilidade construído por laboratório (HSFCM), usando o Lactobacillus casei como cepa.

A limitação deste estudo foi na aquisição dos frascos de leite fermentado de apenas um supermercado, o que impossibilita a comparação com o produto comercializado em outros supermercados que possam ter sofrido abuso de temperatura, pois aponta-se a relevância da temperatura de estocagem como fator contribuinte para a baixa quantia de unidades formadoras de colônia (SILVA; UENO, 2013). 


\section{CONCLUSÃO}

Todos os dez leites fermentados avaliados no decorrer deste estudo estão de acordo com a legislação em vigor do MAPA. Avaliou-se a temperatura de comercialização e o número de unidades formadoras de colônias, o que se evidenciou por meio da contagem de bactérias lácticas probióticas, classificando-os em produtos capazes de promover melhorias à saúde do consumidor.

Contudo todos os produtos com alegação funcional devem ser devidamente prescritos conforme orientação nutricional, pois a melhor opção será aquela que se adequa ao estado nutricional e condições clínicas de cada indivíduo. Apesar de não haver contraindicação ao uso de tais produtos, ressalta-se a necessidade de avaliação nutricional prévia diante de algumas patologias, como diarreia, constipação, intolerância à lactose, Diabetes mellitus, entre outras, fazendo-se necessário um acompanhamento individualizado por nutricionista, para correta prescrição do alimento funcional.

\section{REFERÊNCIAS}

ALMEIDA, D. M. et al. Determinação do tempo de vida de prateleira de iogurte com de polpa de fruta por meio da população de bactérias láticas totais. Revista Brasileira de Tecnologia Agroindustrial, v. 9, n. 1, p. 1671-1681, 2015.

AYENI, F. A.; RUPPITSCH, W. Antagonistic and Quantitative Assessment of Indigenous Lactic acid Bacteria in Different Varieties of Ogi against Gastrointestinal Pathogens. The Pan African medical jornal, v. 27, p. 1-11, 2017.

BALLARDIN, A. C. et al. Análise de microrganismos presentes em amostras de leite fermentado durante a vida de prateleira do produto. Congresso de Pesquisa e Extensão da Faculdade da Serra Gaúcha. v. 2, n. 2, p. 388-399, 2014.

BRASIL. Ministério da Saúde. Instrução Normativa n. 46, de 23 de outubro de 2007. Aprova os Regulamentos Técnicos de Identidade e Qualidade de Leites Fermentados. Diário Oficial da União, Brasília, 2007.

BRASIL. Ministério da Saúde. Instrução Normativa $n^{\circ}$. 44, de 15 de dezembro de 2015. Aprova o regulamento técnico sobre aditivos para produtos destinados à alimentação animal, apresentando os procedimentos a serem adotados na avaliação, registro, comercialização e uso dos aditivos na alimentação animal, a fim de garantir um nível adequado de proteção da saúde humana, dos animais e do meio ambiente. Diário Oficial da União, Brasília, 2015.

BUENO, M. M. Desenvolvimento e aceitabilidade de pão de forma enriquecido com polidextrose e flocos de quinoa. Trabalho de Conclusão de Curso (Graduação em Tecnologia em Alimentos). Instituto Federal de Educação, Ciência e Tecnologia do Rio Grande do Sul, Bento Gonçalves, 2013.

CASTILHO, N. P. A. et al. Enumeração de bactéria lácticas de leites fermentados comercializados em Viçosa, MG. Anais IV SIMPAC, v. 4, n. 1, p. 171-176, 2012. 
COSTA, M. P. et al. Leite fermentado: potencial alimento funcional. Enciclopédia Biosfera, v. 9, n. 16, p. 1387-1408, 2013.

FLESCH, A. G. T.; POZIOMYCK, A. K.; DAMIN, D. D. C. The therapeutic use of symbiotics. Arquivos Brasileiros de Cirurgia Digestiva. v. 27, n. 3, p. 206-209, 2014.

FORSYTHE, S. J. Microbiologia da segurança dos alimentos. Porto Alegre: Artmed Editora; 2013.

HAENLEIN, G. About the evolution of goat and sheep milk production. Small Ruminant Research. v. 68, n. 1-2, p. 3-6, 2007.

HARRIS, H. M. B. et al. Phylogenomics and comparative genomics of Lactobacillus salivarius, a mammalian gut commensal. Microbial Genomics, v. 3, n. 8, 2017.

$\mathrm{HE}$, S. et al.. Rapid quantification of live/dead lactic acid bacteria in probiotic products using high-sensitivity flow cytometry. Methods and Applications in Fluorescence, v. 5, n. 2, p. 2017.

MAIA, L.; SANTOS, Â. Alimentos e suas ações em sistemas fisiológicos. Veredas Favip. v. 3, n. 1/2, p. 24-34, 2006.

MOTA, M. C. et al. Bolo light, diet e com alto teor de fibras: elaboração do produto utilizando polidextrose e inulina. Revista Instituto Adolfo Lutz. v. 70, n. 3, p. 268-275, 2011.

NESPOLO, N. M. et al. Ocorrência de Escherichia coli sorbital negativas em matadouro figorífico de bovino e suscetibilidade e antimicrobianos. Arquivos do Instituto Biológico, v. 81, n. 3, p. 209-2017, 2014.

RIZZARDINI, G. et al. Evaluation of the imune benefits of two probiotic strains Bifidobacterium animalis spp. Lactis, BB- $12^{\circledR}$ and Lactobacillus paracasei ssp. paracasei, L. casei $431^{\circledR}$ in an influenza vaccination model: a randomised, doubleblind, placebo-controlled study. The British jornal of nutrition, v. 107, n. 6, p. 876884, 2012.

ROBERFROID, M. Functional food concept and its application to prebiotics. Digestive and Liver Disease, v. 34, n. 2, p. S105-S110, 2002.

SAAD, S. M. I. Probióticos e prebióticos: o estado da arte. Revista Brasileira de Ciências Farmacêuticas. v. 42, n. 1, p. 1-16, 2006.

SCARIOT, M. C. et al. Quantification of Lactobacillus paracasei viable cells in probiotic yoghurt by propidium monoazide combined with quantitative PCR. International journal of food microbiology, v. 264, p. 1-7, 2017.

SHARMA, C. et al. Antibacterial effects of Lactobacillus isolates of curd and human milk origin against food-borne and human pathogens. 3 Biotech. v. 7, n. 1, p. 30-31, 2017.

SILVA, A. B. N.; UENO, M. Evaluation of lactic acid bacteria viability and titratable acidity variation in fruit flavor yogurt. Revista do Instituto de Laticínios Cândido Tostes, v. 68, n. 390, p. 20-25, 2013. 
SILVA, N.; JUNQUEIRA, V. C.; SILVEIRA, N. F. Manual de métodos de análise microbiológica de alimentos. São Paulo: Varela; 2001.

TAVERNITI, V.; GUGLIELMETTI, S. The immunomodulatory properties of probiotic microorganisms beyond their viability (ghost probiotics: proposal of paraprobiotic concept). Genes \& nutrition, v. 6, n. 3, p. 261-274, 2011.

VILLENA, J.; KITAZAWA, H. Probiotic Microorganisms: A Closer Look.

Microorganisms. v. 5, n. 17, p. 1-3, 2017.

YILDIZ, F. Development and Manufacture of Yogurt and Other Functional Dairy Products. New York: CRC Press; 2010. 